\title{
Review: intravenous and oral opioids reduce chronic non-cancer pain but are associated with high rates of constipation, nausea, and sleepiness
}

Kalso E, Edwards JE, Moore RA, et al. Opioids in chronic non-cancer pain: systematic review of efficacy and safety. Pain $2004 ; 112: 372-80$.

\section{$Q$ Are opioids effective and safe for reducing chronic non-cancer pain?}

\section{METHODS}

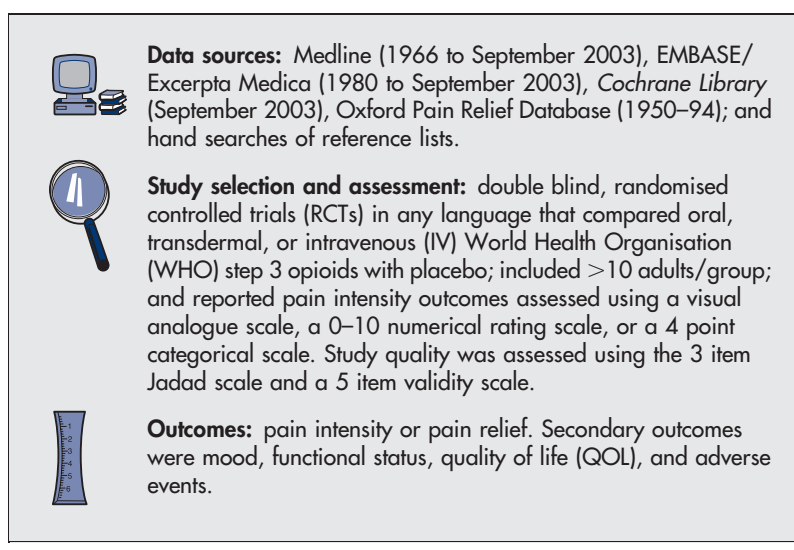

\section{MAIN RESULTS}

15 RCTs met the selection criteria. Mean study quality score was 4 out of 5, and mean validity score was 14 out of 16 . IV opioids. Chronic pain conditions investigated were postherpetic neuralgia (PHN), neuropathic pain, central pain, and phantom pain. 4 trials $(n=120)$ compared IV opioids with placebo. Of these, each of 3 trials (morphine, $18 \mathrm{mg} / 40 \mathrm{~min}$ and $19 \mathrm{mg} / 60 \mathrm{~min}$; and fentanyl, 0.87 $\mathrm{mg} / 5 \mathrm{~h}$ ) found greater pain relief in patients who received opioids than those who received placebo (average pain relief 30\% to $>60 \%$ with opioids and a $5 \%$ increase to $25 \%$ decrease in pain with placebo; $\mathrm{p}$ values 0.0001 to 0.04 ). Oral opioids. A variety of chronic pain conditions were investigated. 11 trials $(\mathrm{n}=1025)$ compared oral opioids with placebo. Of these, each of 8 trials found greater pain relief in patients who received opioids (morphine, $83.5-120 \mathrm{mg} / \mathrm{d}$ or oxycodone 40-45 mg/d) than those who received placebo (mean maximum decrease in pain intensity $10 \%$ to $>60 \%$ with opioids and $4 \%$ to $30 \%$ with placebo; p values 0.0001 to 0.01 ). 6 trials found that groups did not differ for depression scores, and 5 trials found no difference between groups for self reported levels of overall activity or physical function. 7 trials found that opioids improved quality of sleep. More patients who received opioids reported $\geqslant 1$ adverse event

For correspondence: Professor E Kalso, Helsinki University Central Hospital, Helsinki, Finland. eija.kalso@helsinki.fi

Source of funding: no external funding. than those who received placebo (table). 5 studies reported on signs of withdrawal, and 2 studies observed withdrawal in 4 patients.

\section{CONCLUSION}

Intravenous and oral opioids reduce pain intensity in the short term in patients with chronic non-cancer pain but are associated with a higher rate of adverse events than placebo.

\section{Commentary}

7 he use of strong acting opioid analgesics for management of chronic non-cancer pain continues to be controversial despite the advent of consensus statements. ${ }^{12}$ The well conducted systematic review by Kalso et al on the efficacy and safety of opioids for this patient population is an important contribution to knowledge. All reviewed studies had good quality and validity scores and provided consistent evidence on the short term benefits of opioids for pain relief. However, other outcomes, such as quality of life and overall functioning, were assessed in only a few studies. Furthermore, only 6 studies assessed the long term effects $(6-24 \mathrm{mo}$ ) of opioids, and all had unblinded follow up. The authors reported that only $44 \%$ of patients continued on long term therapy. These studies did not report on negative outcomes of opioids such as addiction, which are of concern to patients, the public, and healthcare providers.

The results of the review by Kalso et al are relevant to nurses who work with patients with chronic non-cancer pain in pain clinics, hospitals, or community settings. At least 2 relevant clinical implications exist from this review. Firstly, pain reductions varied between studies. Secondly, the higher rate of adverse events in the opioid group highlights the dilemma of balancing potential pain relief with safety concerns (rate of adverse events was high in both groups ( $80 \% \vee 56 \%)$. These findings support the need to institute preventive measures for such common side effects as constipation and nausea and to closely monitor patients who are taking opioids.

The review by Kalso et al clearly identified the need for longer follow up studies in patients with chronic pain, particularly patients with addiction who have previously been excluded from research studies of opioid use.

Sandra M LeFort, RN, PhD School of Nursing, Memorial University of Newfoundland St John's, Newfoundland, Canada

1 Jovey RD, Ennis J, Gardner-Nix J, et al. Use of opioid analgesics for the treatment of chronic noncancer pain - a consensus statement and guidelines from the Canadian Pain Society, 2002. Pain Res Manag 2003;8/Suppl A):3A-28A.

2 The Pain Society. Recommendations for the appropriate use of opioids for persistent non-cancer pain. March 2004. Accessed April 2005. http:// www.britishpainsociety.org/pdf/opioids_doc_2004.pdf

Opioids $v$ placebo for chronic non-cancer pain*

\begin{tabular}{llllll}
\hline Outcomes at 6-24 months & Number of trials $(\mathbf{n})$ & Opioids & Placebo & RRI (95\% Cl) & NNH (CI) \\
\hline ? 1 adverse event & $4(445)$ & $80 \%$ & $56 \%$ & $40 \%(30$ to 60$)$ & $4(3$ to 6$)$ \\
Constipation & $8(1114)$ & $41 \%$ & $11 \%$ & $260 \%(170$ to 370$)$ & 3 to 4$)$ \\
Nausea & $8(1114)$ & $32 \%$ & $12 \%$ & $170 \%(110$ to 260$)$ & $5(4$ to 6$)$ \\
Sleepiness/sedation & $7(1022)$ & $29 \%$ & $10 \%$ & $230 \%(140$ to 350$)$ & 5 (4 to 7$)$ \\
\hline
\end{tabular}

*Abbreviations defined in glossary; RRI, $\mathrm{NNH}$, and $\mathrm{Cl}$ calculated from data in article. 